\title{
MaiMwana women's groups: a community mobilisation intervention to improve mother and child health and reduce mortality in rural Malawi
}

\author{
Mikey Rosato ${ }^{1}$, Charles Mwansambo ${ }^{2}$, Sonia \\ Lewycka $^{1}$, Peter Kazembe ${ }^{3}$, Tambosi Phiri ${ }^{4}$, \\ Florida Malamba4, Marie-Louise Newell ${ }^{5}$, \\ David Osrin ${ }^{1}$, Anthony Costello ${ }^{1}$ \\ 1. Centre for International Health and Development, UCL, Institute of \\ Child Health, 30 Guilford St, London WC1N 1EH. \\ 2. Kamuzu Central Hospital, Ministry of Health, Malawi \\ 3. Baylor College of Medicine Children's Foundation, Malawi, Private \\ Bag 397, Lilongwe \\ 4. MaiMwana Project, PO Box 2, Mchinji, Malawi \\ 5. Africa Centre for Health and Population Studies, University of Kwa- \\ Zulu Natal, Sombkele, South Africa
}

\begin{abstract}
This article presents a detailed description of a community mobilization intervention involving women's groups in Mchinji District, Malawi. The intervention was implemented between 2005 and 2010.

The intervention aims to build the capacities of communities to take control of the mother and child health issues that affect them. To achieve this it comprises trained local female facilitators establishing groups and using a manual, participatory rural appraisal tools and picture cards to guide them through a community action cycle to identify and implement solutions to mother and child health problems. Significant resource inputs include salaries for facilitators and supervisors, and training, equipment and materials to support their work with groups.

It is hypothesized that the groups will catalyse community collective action to address mother and child health issues and improve the health and reduce the mortality of mothers and children. Their impact, implementation and cost-effectiveness have been rigorously evaluated through a randomized controlled trial design. The results of these evaluations will be reported in 2011.
\end{abstract}

\section{Introduction}

Malawi has high rates of maternal and neonatal mortality and morbidity ${ }^{1}$. Since 1990 , the country has made progress towards achieving the target of Millennium Development Goal (MDG) four, reducing under-five mortality by twothirds, and of MDG five, reducing maternal mortality by half by 2015 , but like other countries in sub-Saharan Africa, the progress has been insufficient ${ }^{2}$. Amidst the existing resource constraints, it is unlikely that Malawi will achieve these targets through current policies and strategies. As a result, amongst other approaches, Malawi would benefit from exploring the potential of community involvement for improving maternal and neonatal health and reducing mortality ${ }^{3}$.

Community mobilization through women's groups has been shown to be effective and cost-effective in changing care and care-seeking practices and reducing mortality in rural Bolivia, Nepal and India ${ }^{4,5,6}$. This approach, if equally successful in Malawi and other countries in sub-Saharan Africa, could contribute towards the achievement of MDG four and five in the region.

This paper describes the design of a women's group community mobilisation intervention that was implemented and rigorously evaluated in Mchinji District, Malawi between 2005 and 2010. To allow comparability the intervention will be framed in a standard manner in terms of its aims, setting, target group, objectives and resources?. The intervention was implemented after receiving permission from the Mchinji
District Executive Committee and the Malawi National Health Sciences Research Committee.

\section{Aims: What is the aim of the women's group intervention?}

The intervention aimed to build the capacities of communities in rural Malawi to take control of the mother and child health issues that affect them such as the high rates of mortality and morbidity they are facing, their low practice of key care and care-seeking behaviours and their high levels of disadvantage and disempowerment.

\section{Setting: What is the context in which the women's group intervention was implemented?}

\section{Location}

MaiMwana Project is a research and development collaboration between the Malawi Ministry of Health (The Department of Paediatrics at Kamuzu Central Hospital and Mchinji District Hospital) and the UCL Centre for International Health and Development in the UK. The project was established in 2003 and is conducting the first randomized controlled trial evaluation of this approach in an African context characterized by a high maternal mortality rate and HIV and malaria prevalence . $^{8}$.

The project is implementing the women's groups in Mchinji District, Malawi (Figure 1). The total population of Malawi in 2008 was $13077160^{1}$. It ranks 160 out of 182 countries in the Human Development Index, has a Gross National Product of $\$ 690$ per capita, $73.9 \%$ of the population live below the poverty line of less than $\$ 1.25$ per day and $90.4 \%$ live below the poverty line of $\$ 2$ per day ${ }^{9,10,11}$. Life expectancy at birth for both men and women is 48 years ${ }^{11}$. Some key maternal and child health indicators for Malawi are presented in Table 1.

Mchinji District is one of nine administrative districts in the Central Region of Malawi (Figure 2). It lies to the west of Lilongwe, the capital city, and has international borders with Zambia and Mozambique. It covers an area of 3356 square kilometres and has a population of $456516,80 \%$ of which is rural (1). Mchinji is divided into 9 Traditional Authorities (TAs): Dambe, Kapondo, Mavwere, Mduwa, Mkanda, Mlonyeni, Nyoka, Simpasi and Zulu. These TAs consist of a total of over 1000 villages. The district headquarters is Mchinji Boma, the site of the MaiMwana Project office.

\section{Demography and health services}

Half of the district population (49.4\%) is aged between 15 and $64^{1}$. Most of the population is Christian (93.6\%) and the other main religious group is Muslim, but these only account for $2.9 \%$ of the population ${ }^{1}$. Just over a quarter of the population aged over five years have attended primary school $(26.1 \%)$, but only $1.7 \%$ have attended secondary school and $0.1 \%$ higher education ${ }^{12}$. Some key maternal and child health indicators for Mchinji District are presented in table 1.

In Mchinji, maternal and perinatal health care is provided by personnel at one district hospital (a first referral and secondary health facility), four rural community hospitals (one 
government and three managed by the Christian Hospital Association of Malawi), one maternity unit, six health centres that provide maternity care and two private clinics that offer antenatal care. There are also two dispensaries but these do not offer antenatal or delivery care. There are around 750 people per hospital bed. Traditional Birth Attendants (TBAs) are also available in most localities.

\section{Women's group clusters and study design}

The women's group intervention was implemented within a factorial cluster randomized controlled trial designed to assess the impact of the groups on maternal, perinatal, neonatal and infant mortality and morbidity ${ }^{8}$. A second intervention was implemented simultaneously, using volunteer infant feeding and care counselors to promote behaviour change ${ }^{13}$. MaiMwana Project also collaborated with the District Health Office in a range of district wide activities including rollout of PMTCT services, male championship, health facility staff supervision and community maternal death reviews.

At baseline the total district population, excluding the population of Mchinji Boma, was divided into 48 clusters of similar size, and from these a total study population of 145 426 from 692 villages and 28028 households was selected. 12 of the clusters were randomly allocated to receive women's groups as the only intervention; 12 to receive volunteer counseling as the only intervention; 12 to receive both interventions; and the final 12 to receive neither intervention (figure 2). At baseline, within the 24 women's group clusters there were 336 villages with a total population of 72129 people including 21376 were women of childbearing age (aged between 15 and 49 years of age). Some key maternal and child health indicators for the women's group clusters are presented in Table 1 .

\section{Target group: Who is intended to change as a result of the women's groups?}

The primary population targeted by the intervention was women of childbearing age and their children living in the 24 rural clusters receiving the women's group intervention. Data collected by MaiMwana showed that on average, the women in the target group were 23 years of age and most were Chewa (84.7\%) and Christian (96.0\%) (Table 2). MaiMwana data also suggested that farmers $(56.8 \%)$ and students $(30.5 \%)$ made up most of the target group, of which almost one quarter $(23.2 \%)$ had received no formal education, $70.2 \%$ had received primary education as their highest level of achievement, $6.4 \%$ had received secondary education, and only $0.4 \%$ had received tertiary education. MaiMwana collected data on key maternal and child health indicators. Firstly, this showed that most women in the target group were married $(55.5 \%)$ and had previously been pregnant $(58.2 \%)$. Secondly, in terms of additional pregnancy care and care seeking indicators $11.7 \%$ had received voluntary counseling and testing for HIV (VCT) during antenatal care, and $42.6 \%$ had slept under an insecticide treated net (ITN) on the night preceding data collection (table 3). Thirdly, regarding additional birth care and care seeking indicators: approximately one third $(36.0 \%)$ gave birth with a skilled provider and $41.2 \%$ gave birth with a TBA. Finally, regarding additional postnatal care and care seeking indicators, almost all $(93.3 \%)$ wrapped their baby within 30 minutes of birth, just under one third $(31.5 \%)$ bathed their baby after 24 hours, and three quarters $(77.5 \%)$ initiated breastfeeding within one hour. The target group included all other women aged over 49 and girls under 15 as a secondary target population. Younger girls who had not yet reached childbearing age were targeted because in the future they were expected to become pregnant and give birth. Older women were targeted because they had important experiences that they could share with women and girls. Finally, the target group included all men and boys as a tertiary target population as they were expected to play an important role in relation to mother and child health.

\section{Objectives: What activities does the women's group intervention consist of?}

To achieve its aims the women's group intervention consisted of the following components: groups, members, a cycle of meetings, participatory rural appraisal tools, and picture cards.

Groups From May 2005, 310 villages in allocated clusters chose to establish 207 women's groups. Currently, 197 groups are still active, eight groups chose to disband and two chose to amalgamate with other nearby groups.

Members The exact criteria for group membership (for example, age and marital status) were decided by the groups themselves. However, in Phases 1 and 2 of the cycle (see below) the groups had a membership restricted to only women and girls. Although men were invited to attend two meetings (meeting 8 in Phase 1 and meeting 12 in Phase 2) they were not involved in decision-making or discussion of sensitive topics until Phase 3 and Phase 4 when they formally became members of the groups. In these latter phases it was not uncommon for men to take on roles such as chairperson or secretary as well as being group members. Over 12 000 women and men attended the groups at least once, with approximately 8000, 6000, 10000 and 7500 attending Phases 1,2, 3 and 4 respectively. MaiMwana women's group cycle of meetings Each group progressed through a community mobilisation action cycle based on the women's group model initially developed by WARMI in Bolivia ${ }^{14}$ and subsequently implemented by Mother and Infant Research Activities (MIRA) in Makwanpur, Nepal ${ }^{15}$. A similar model is also being implemented by in Dhanusha District (Nepal), Mumbai municipality and Jharkhand and Orissa States (India), Salima, Kasungu, Lilongwe and Ntcheu districts (Malawi) and Bogra, Faridpur and Moulavibazar districts (Bangladesh). The model implemented by MaiMwana was developed to be appropriate, accessible and feasible for the Malawian context through an in-depth process of piloting and formative research in 2004 and 2005. The cycle consisted of four phases and 20 monthly meetings (figure 4). Phase 1. Identifying and prioritizing problems together (eight meetings).

The aim of this phase was for groups to form, to identify all the maternal and neonatal problems that affect people in their communities, prioritize which ones they feel are most important and need to be addressed, and share with each other what contributes to the problems and how they can be prevented and managed. The maternal health problems most commonly identified and prioritized by groups include hemorrhage, anaemia, malaria, retained placenta and obstructed labour. The neonatal and infant health problems most commonly identified and prioritized by groups include diarrhoea, infection, preterm birth, tetanus and malaria. The process and results of identification and prioritization of maternal, neonatal and infant health problems are discussed in more detail in other publications ${ }^{15,16}$. Furnished with this information, the women's group members convened a meeting with men to present everything they have discussed, 
explain what they are hoping to do in the future, gather their opinions and ideas and answer any questions they have.

\section{Phase 2. Planning solutions to problems together (four meetings)}

The aim of this phase was for groups to take the priority problems they identified in the previous phase, and what they had learnt about contributing factors and preventative and management activities, and identified strategies that could feasibly address the priority problems they identified making best use of local resources. The strategies most commonly identified by groups included health education, bicycle ambulances, training for TBAs, cultivation of vegetable gardens and distribution of ITNs. The group then invited all community members to a meeting and presented their plans, while at the same time explaining what they hoped to do in the future, gathering opinions, ideas and pledges of support from the community and answering any questions.

\section{Phase 3. Implementing solutions together (four meetings)}

The aim of this phase was for groups to take the strategies identified in the previous phase and put them into practice. The group could choose to implement all the strategies at one time or to implement them sequentially. The group could also decide to work together on the strategies or to split into different taskforces responsible for each strategy. The strategies most commonly implemented included: health education, bicycle ambulances, cultivation of vegetables gardens, distribution of ITNs, establishment of mobile antenatal and under-five clinics, small-scale IGAs, distribution of ORS and group funds.

\section{Phase 4. Evaluating together (four meetings)}

The aim of this phase was for groups to evaluate how they had operated and the strategies they had implemented to review what had happened in the past and plan for the future.

\section{Tools}

The women's group cycle was supported by three types of tools that could facilitate and stimulate discussion: women's group manuals, participatory rural appraisal (PRA) tools, and picture cards.

\section{Women's group manual}

Thewomen's groupmanual was a guideline forimplementation of the four phases and 20 meetings. It outlined in particular the aims and objectives of each meeting, what needed to be prepared before the meeting, discussion prompts related to the aims and objectives of the meeting, which PRA tools or picture cards can be used to facilitate and stimulate discussion, and what needed to be done after the meeting. It also included a description of the PRA tools that could help to facilitate and stimulate discussion in the meetings covered by the manual, and examples of a number of meeting monitoring forms that should be completed to record what was achieved.

\section{Participatory rural appraisal tools}

A choice of PRA tools was provided for the groups to help facilitate and stimulate the major discussions they undertook during the different phases of cycle. Together with their facilitators (see below) the groups were able to choose from tools that helped to identify problems, prioritise problems, identify contributing factors, identify strategies and their potential opportunities and barriers and evaluate the groups and the strategies (Box 1).

Box 1: Participatory rural appraisal tools

- Tools to facilitate the identification of problems (Meetings

2 and 3): body mapping (the group draws a woman or a baby and indicates where on the body the woman or

baby might be afflicted by problems at different stages of pregnancy, delivery or after birth); timeline (the group draws a timeline for a woman or a baby and indicates different stages of pregnancy, delivery or after birth on it, and the problems that might afflict the woman or baby at these different stages); stories (the group reads out a story of a woman or baby who experienced some health problems and then discusses what other problems they might experience)

- Tools to facilitate the prioritization of problems (Meeting 5): preference ranking (blind ranking with each group member able to vote for the problem she feels is most important); pair-wise ranking (the group systematically compares each problem to every other problem); diamond ranking (the group sorts the problems into an order of importance).

- Tools to facilitate the identification of contributing factors (Meeting 6): cause-effect diagram (the group assesses each problem in terms of input arrows (causes) and output arrows (effects); problem tree (the group assesses each problem - tree trunk - in terms of its inputs - roots - and outputs - branches and leaves; but why? (the group

assesses each problem by asking 'but why' did it arise until the root contributing factors are identified)

- Tools to facilitate the identification of solutions and resources and barriers for them (Meeting 10): H-exercise; bridge the gap; balloon (all three of these tools are different visualizations of the same process which enables groups to illustrate where they are in relation to an issue, where they want to be and how they plan to get there - the

strategies. It also allows for groups to explore the factors that might facilitate or hinder the implementation of the strategies).

- Tools to facilitate the evaluation of groups and strategies (Meetings 18 and 19): spider diagram; graph.

\section{Picture cards}

In addition to the PRA tools, picture cards were also used to facilitate and stimulate discussion. There were 60 picture cards, divided into four types: problem cards, contributing factor cards, preventative activity cards and management activity cards (Box 2). 


\section{Box 2: Picture cards}

-Problem cards (21 cards): cover the main health problems affecting mothers and babies in Malawi. For example, malaria and antepartum heamorrhage.

-Contributing factor cards (17 cards): cover the main contributing factors to problems. for example, not sleeping under a bednet and working too hard while pregnant.

-Preventative activity cards (13 cards): cover the main activities people can perform to prevent problems affecting mothers and babies from arising. For example, clearing the surroundings of houses and going for an antenatal checkup.

-Management activity cards (9 cards): cover the main activities people can perform to manage problems affecting mothers and babies once they have already arisen. For example, going to a health facility without delay and early and exclusive breastfeeding.

The cards were used to stimulate further discussion, clarify what had already been identified, visualize links and relationships, summarise and illustrate what the problems were, what caused them and how they could be prevented and managed. The cards were only presented after the issue depicted on the card had already been identified by the group, to allow for further discussion. They were not presented if the issue they depicted had not been identified or used to prompt the groups to identify the issues that they depicted $^{17}$.

\section{Resources: What resources are required to implement the women's groups?}

The most significant resource inputs for the women's group intervention were the zonal facilitators (ZFs) and supervisors employed to run the intervention. These members of staff received a salary, training and equipment and materials to conduct their work.

\section{Facilitators}

In October 2004, one facilitator was recruited in each of the 24 clusters. ZFs were interviewed and selected on the basis of a number of criteria, including coming from a village within the cluster they hoped to work in, being literate in Chichewa, having at least a Junior Certificate of Education (JCE), and preferably a Malawi School Certificate of Education (MSCE), having at least one child, and being aged between 20 and 49. Having previous experience of working in community development was also desirable. Since the beginning of the project four ZFs have been replaced. The ZFs began implementing the intervention in women's group communities in May 2005.

The role of the ZFs was to form groups - each ZF formed between four and 12 groups in their area - and facilitate them through the community mobilization action cycle. They did this by using the manuals, PRA tools and picture cards to form groups and guide them through the four phases and 20 meetings of the MaiMwana women's group cycle. They monitored this process by filling in monitoring forms after each group meeting. The role of the ZF, particularly in Phase 2 and 3, was also to train group members in necessary skills, advocate for the groups at the local level and liaise with community level group stakeholders and partners. To enable them to carry out these activities the ZFs received an initial 11-day residential training in November 2004 and 5-day residential 'refresher' trainings approximately every four months. The ZFs received extensive training in community mobilization but since they were not health workers they have received only basic training in issues specifically relating to maternal and neonatal health.

The ZFs received a salary of approximately $£, 40$ per month, a bicycle, a T-shirt, an umbrella, a field bag, a copy of the women's group manuals, a set of picture cards, stationery and adequate numbers of printed monitoring forms.

Supervisors and senior supervisor Four supervisors and one senior supervisor were recruited in September 2004. These supervisors had extensive experience of community development work. The district was divided into four nodal areas, each covering an average of 12 clusters, of which six were women's group clusters. An office was established at a central point in each nodal area (Kamwendo, Kapiri, Mkanda and Waliranji), and the four supervisors were posted to live in these areas and work from the nodal offices. The senior supervisor was based at the project head office in Mchinji Boma. The role of the supervisors was to oversee the work of the six ZFs and associated groups in their nodal areas. In terms of fieldwork, supervisors visited each ZF approximately twice per month to observe the meeting being conducted, feed back constructive criticism to the ZFs about their facilitation skills and address problems that had arisen. In terms of office work, supervisors hold a monthly meeting at their nodal office, attended by all six ZFs in the nodal area, and facilitated a team discussion in which ZFs shared achievements and challenges and identified potential strategies to address them. The supervisors met monthly with the senior supervisor at the head office. The other role of the supervisors and senior supervisor was to train the ZFs generally in facilitation and community mobilization, and specifically to use the manual, PRA tools, picture cards and monitoring forms. This training was conducted on an ad-hoc basis during supervisory visits and monthly meetings, and also formally at the four monthly residential refresher trainings.

The supervisors receive a salary of between $£ 200$ to $£ 350$ per month, the shared use of a motorcycle, riding equipment, a T-shirt, fuel, stationery and adequate numbers of printed monitoring forms. Other major inputs for the supervisors and senior supervisor included office rent and capital equipment expenditure for computers, furniture and other office resources.

\section{Resources to implement strategies identified by women's groups}

MaiMwana Project did not provide any resources to the groups to enable them to implement their strategies. The role of the project was purely to build capacity in the groups to take control of their mother and child health issues by offering support, training and technical advice where necessary. The project also had a role in advocating for the groups and linking them directly to appropriate organisations locally, regionally and nationally. As a result, if groups needed resources to implement a strategy they had to draw on the capacities they had developed to mobilize this either from within their own communities or through links to other government and non-governmental organizations working in the area. 


\section{Discussion}

The intervention described in this paper seeks to reduce maternal, neonatal and infant mortality and morbidity in Mchinji District, Malawi, by mobilizing communities through women's groups. These groups seek to address the psychosocial risk factors and risk conditions that underpin poor health ${ }^{18,19}$ by developing the assets and capacities of communities to be organized, concerned about and ready and able to address the broader determinants of maternal and neonatal health - empowered in the sense that they are ready to take social and political action. As such, the intervention is community based in that it defines the community as the agent of change ${ }^{20}$.

Rissel $^{21}$ and subsequently others including Labonte ${ }^{19}$, conceptualized community empowerment as a process along a dynamic five-point continuum representing progressively more organized and broadly-based forms of collective and social action: personal action; small mutual groups; community organizations; partnerships; and social and political action. When they are first formed women's groups can be conceptualized as small mutual groups that gradually through the cycle diversify into community organizations (particularly in Phase 3). In this way the groups are pivotal to the process of generating greater social organization and mobilization and thus to addressing maternal and neonatal health issues - they are the genesis of collective action. They form the fundamental link between individuals in communities and partners within and outside communities because it is only by participating in small groups or organizations that individual community members can better define, analyze and act on issues of concern ${ }^{22}$. In addition, it is through community organizations that individuals gain the skills and networks necessary to allow small groups to make the transition to partnerships and later to social and political action $^{22}$. As a result, it is through groups that the assets and capacities of individuals and partners can converge and ignite social and political action, which may help to reduce maternal and neonatal mortality and morbidity.

The impact of the groups on mortality and morbidity will be published in 2011 together with detailed information on their implementation, cost-effectiveness and non-health benefits.

\section{Funding}

The MaiMwana Project study is funded by two grants from Saving Newborn Lives (Save the Children, USA) and a Wellcome Trust Strategic Award. Additional funding for PMTCT service strengthening was received from UNICEF, Malawi, and the National AIDS Commission, Malawi.

\section{Competing interests}

The authors declare that they have no competing interests.

\section{Acknowledgements}

The trial funding was initially provided by Saving Newborn Lives with later contributions from the UK Department for International Development, the Wellcome Trust, and UNICEF Malawi. We thank the many individuals in Mchinji District without whom the study would not have been possible. We particularly wish to thank members of all communities in which the project is working; the Maimwana office and field staff involved in running, monitoring and evaluating the interventions; the District Health Officers and District Health Management Team for their ongoing support, the Mchinji District Executive Committee, traditional leaders and other non-governmental organizations working in the district.

\section{References}

1.National Statistics Office Malawi, OCR Macro. Malawi Demographic and Health Survey 2004. Calverton, Maryland: NSO and OCR Macro, 2005.

2.United Nations. The Millennium Development Goals Report 2009. United Nations, 2009.

3.Malawi Ministry of Health. Road map for accelerating the reduction of maternal and neonatal mortality and morbidity in Malawi. Malawi Ministry of Health; 2005.

4.O'Rourke K, Howard-Grabman L, and Seoane G. Impact of community organization of women on perinatal outcomes in rural Bolivia. Rev Panam Salud Publica, 1998. 3(1): p. 9-14.

5.Manandhar D.S, Osrin D, Shrestha B.P, Mesko N, Morrison J, Tumbahangphe K.M, Tamang S, Thapa S, Shretha D.S, Thapa B, Shrestha J.R, Wade A, Borghi J, Standing H, Manandhar M and Costello A. Effect of a participatory intervention with women's groups on birth outcomes in Nepal: cluster-randomised controlled trial. Lancet, 2004. p. $970-9$.

6. Tripathy P, Nair N, Barnett S, Mahapastra R, Borghi J, Rath S, Rath S, Gape R, Mahto D, Sinha R, Lakshminarayan R, Patel V, Pagel C, Prost A and Costello A. Effect of a participatory intervention with women's groups on birth outcomes and maternal depression in Jharkhand and Orissa, India: a cluster-randomised controlled trial. Lancet, 2010. 375: p. 1182-1192.

7. Hickson FCI. Tools For Map Making. London. 1999 Sigma Research

8. Lewycka S, Mwansambo C, Kazembe P, Phiri T, Mganga A, Chapota H, Malamba F, Rosato M, Newell ML, Osirn D and Costello A. A randomized controlled trial of the community effectiveness of two interventions in rural Malawi to improve health care and to reduce maternal, neonatal and infant mortality. Trials 2010. 11: p. 88.

9. UNDP. Human Development Report 2009. 2009 Palgrave-MacMillan; New York.

10. The World Bank. World Development Report 2006: Equity and Development. 2006 Oxford University Press; New York.

11. The World Bank. World Development Report 2010. Development and Climate Change. 2010 The World Bank; Washington.

12. National Statistics Office Malawi. 2008 Population and Housing Census. National Statistics Office Malawi, 2008.

13. Lewycka S, Mwansambo C, Rosato M, Kazembe P, Phiri T, Chapota H, Vergnano S, Newell ML, Osrin D and Costello A. Infant Feeding and Care Counselling: a health education intervention to improve mother and child health and reduce mortality in rural Malawi. Malawi Medical Journal (submitted).

14. Howard-Grabman L. The "autodiagnosis": a methodology to facilitate the maternal and neonatal health problem identification and prioritization in women's groups in rural Bolivia. 1993, MotherCare/ John Snow Inc.: Virginia

15. Morrison J, Tamang S, Mesko N, Osrin D, Shrestha B, Manandhar $\mathrm{M}$, Standing H and Costello A. Women's health groups to improve perinatal care in rural Nepal. BMC Pregnancy and Childbirth. 2005. p. 6.

16. Rosato M, Mwansambo C, Kazembe P, Phiri T, Soko Q, Lewycka S, Kunyenge B, Vergnano S, Osrin D, Newell ML and Costello A. Women's groups' perceptions of maternal health problems in rural Malawi. Lancet 2006; 368: 1180-8.

17. Rosato M. Women's groups' perceptions of neonatal and infant health problems in rural Malawi. Malawi Medical Journal 2009; 21 (4): $168-173$

18. Labonte, R. Health promotion and empowerment: Practice frameworks. 1993 Toronto: Centre for Health Promotion/ ParticipAction.

19. Labonte, R. A Community Development Approach to Health Promotion: a Background Paper on Practice Tensions, Strategic Models 
and Accountability Requirements for Health Authority Work on the Broad Determinants of Health. 1998 Health Education Board of Scotland and Research Unit in Health, Behaviour and Change, University of Edinburgh

20. McLeroy K.R, Norton B.L, Kegler M.C, Burdine J.N and Sumaya C.V. Community-Based interventions. Am J Public Health 2003; 93(4), 529-533

21. Rissel C. Empowerment: The holy grail of health promotion?. Health Promotion International 1994: 9(1)

22. Laverack G. Health promotion practice: power and empowerment. 2004 Sage: London

23. National Statistical Office and UNICEF. Malawi Multiple Indicator Cluster Survey 2006, Final Report. 2008 Lilongwe, Malawi: National Statistical Office and UNICEF.
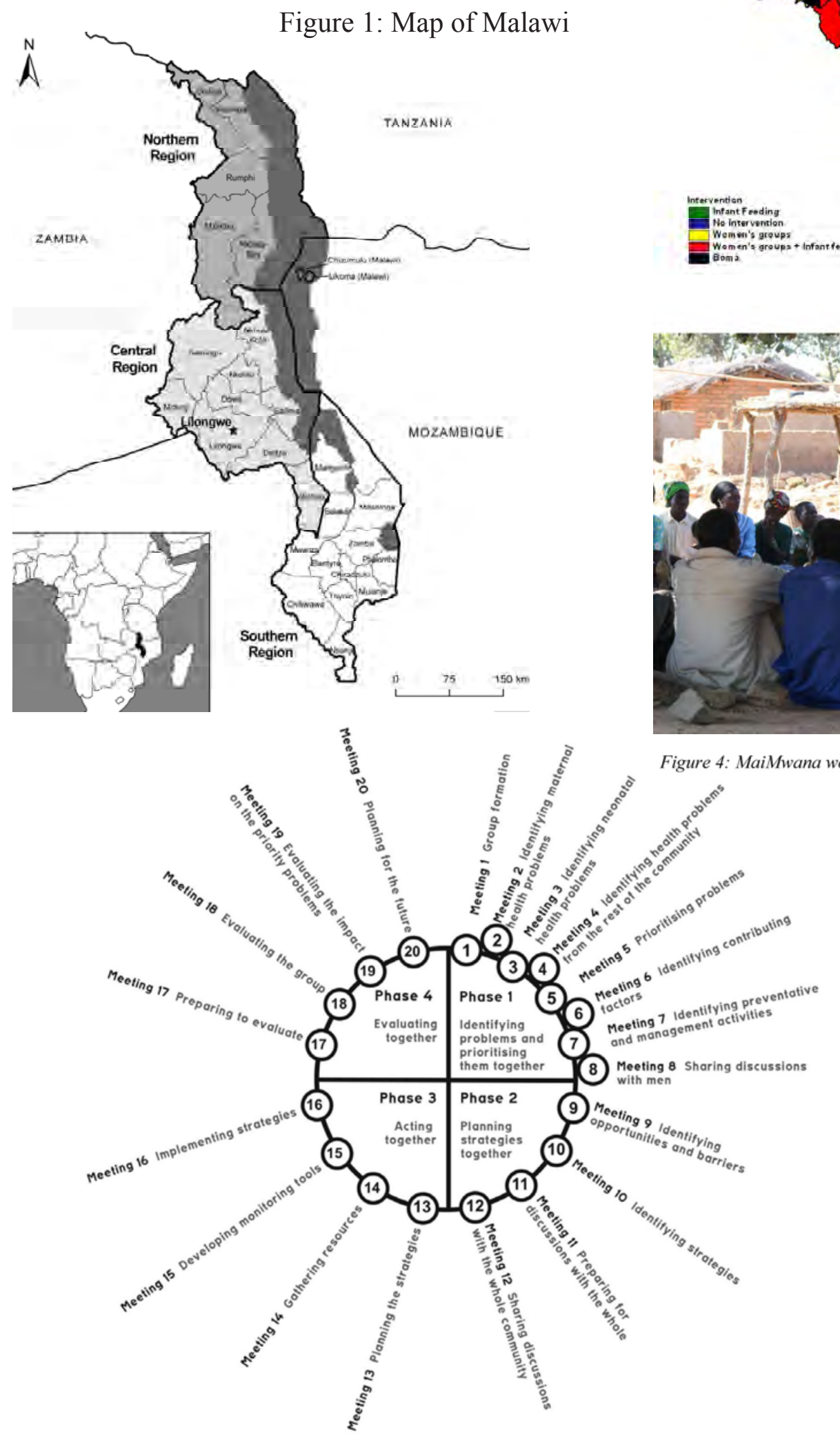

Figure 2: Map of Mchinji District and cluster intervention allocation
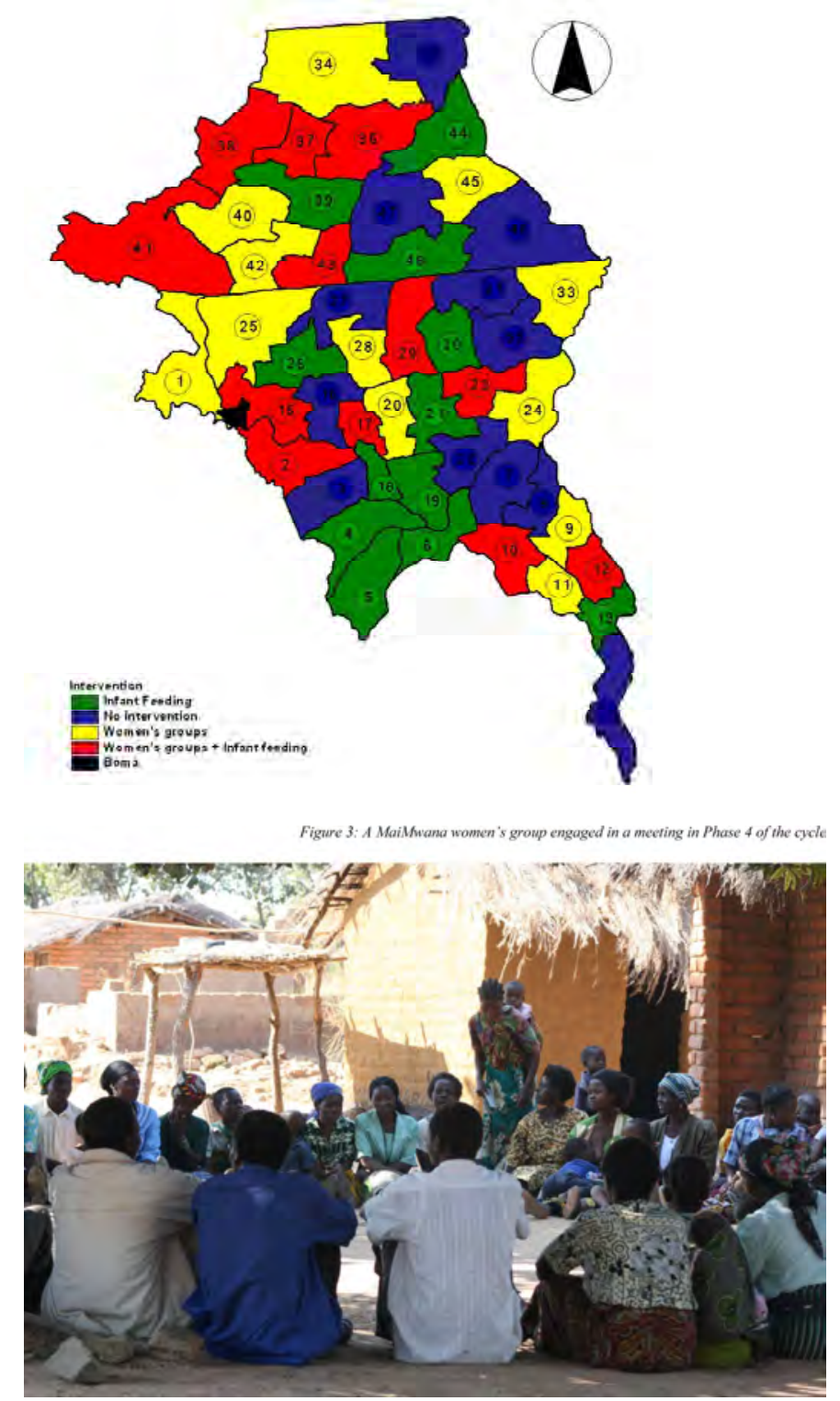

Figure 4: MaiMwana women's group cycle 


\begin{tabular}{|c|c|c|c|c|}
\hline & & Mchinji District & & \\
\hline & Malawi & Published statistics & $\begin{array}{l}\text { MaiMwana Project } \\
\text { data at baseline }\end{array}$ & $\begin{array}{l}\text { Women's group } \\
\text { clusters from MaiMwana } \\
\text { Project data at baseline }\end{array}$ \\
\hline \multicolumn{5}{|l|}{$\begin{array}{l}\text { PREGNANCY AND } \\
\text { BIRTH }\end{array}$} \\
\hline $\begin{array}{l}\text { Antenatal care (ANC) at } \\
\text { least once percentage }\end{array}$ & $97.2^{1}$ & $98.5^{1}$ & $91.6^{4}$ & $91.6^{4}$ \\
\hline $\begin{array}{l}\text { Facility delivery } \\
\text { percentage }\end{array}$ & 53.81 & 57.71 & $39.9^{4}$ & $36.1^{4}$ \\
\hline $\begin{array}{l}\text { Postnatal care (PNC) } \\
\text { within } 42 \text { days } \\
\text { percentage }\end{array}$ & $32.7^{1}$ & $41.3^{1}$ & $28.3^{4}$ & $25.1^{4}$ \\
\hline $\begin{array}{l}\text { Crude birth rate (CBR) per } \\
1000 \text { population }\end{array}$ & $43.9^{1}$ & & $38.8^{4}$ & $37.7^{4}$ \\
\hline $\begin{array}{l}\text { Total fertility rate (TFR) } \\
\text { per woman }\end{array}$ & $6.3^{1}$ & $5.7^{1}$ & & \\
\hline \multicolumn{5}{|l|}{ MORTALITY } \\
\hline $\begin{array}{l}\text { Perinatal Mortality Rate } \\
\text { (PMR) per } 1000 \text { live births }\end{array}$ & $34^{2}$ & & $42^{4}$ & $50^{4}$ \\
\hline $\begin{array}{l}\text { Neonatal Mortality Rate } \\
\text { (NMR) }\end{array}$ & $37^{3}$ & $24^{3}$ & $28^{4}$ & $33^{4}$ \\
\hline $\begin{array}{l}\text { Post-neonatal Mortality } \\
\text { Rate per } 1000 \text { live births }\end{array}$ & $44^{3}$ & $41^{3}$ & & \\
\hline $\begin{array}{l}\text { Infant Mortality Rate (IMR) } \\
\text { per } 1000 \text { live births }\end{array}$ & $81^{3}$ & $65^{3}$ & $50^{4}$ & $65^{4}$ \\
\hline $\begin{array}{l}\text { Child Mortality Rate per } \\
100,000 \text { live births }\end{array}$ & $64^{3}$ & $73^{3}$ & & \\
\hline $\begin{array}{l}\text { Under- } 5 \text { Mortality Rate } \\
\text { per } 100,000 \text { live births }\end{array}$ & $140^{3}$ & $133^{3}$ & & \\
\hline $\begin{array}{l}\text { Maternal Mortality Ratio } \\
\text { (MMR) per } 100,000 \text { live } \\
\text { births }\end{array}$ & $807^{3}$ & & $486^{4}$ & $466^{4}$ \\
\hline & & & & \\
\hline
\end{tabular}

\section{Table 1: Key Health indicators for Malawi}

1.Malawi Population and Housing Census 2008 (12)

2.Malawi Demographic and Health Survey, 2004 (1)

3.Multiple Indicator Cluster Survey, 2006 (23)

4.MaiMwana Project data. This data was collected at baseline in 2004 from a study population of 145426 people. This is a purposive sub-sample of the total district population of approximately 480000 people. More details on methods used to select this sub-sample are presented elsewhere (7) 
Table 2: Key socio-economic and demographic characteristics of women of childbearing age in women's group intervention clusters (women aged 10 - 49 years) collected during mapping from July to September 2004

\begin{tabular}{|c|c|c|}
\hline $\begin{array}{l}\text { Women of childbearing age (aged } 10-49 \text { ) in } \\
\text { intervention clusters during mapping from } \\
\text { July to September } 2004\end{array}$ & & $n=24175$ \\
\hline $\begin{array}{l}\text { Age } \\
\text { mean }\end{array}$ & & 23.34 \\
\hline $\begin{array}{l}\text { Tribe } \\
\text { percentage }\end{array}$ & $\begin{array}{l}\text { Chewa } \\
\text { Ngoni } \\
\text { Senga } \\
\text { Other }\end{array}$ & $\begin{array}{l}84.7 \\
8.2 \\
3.2 \\
3.8\end{array}$ \\
\hline $\begin{array}{l}\text { Religion } \\
\text { percentage }\end{array}$ & $\begin{array}{l}\text { Catholic } \\
\text { Other Christian } \\
\text { Muslim } \\
\text { Other }\end{array}$ & $\begin{array}{l}42.2 \\
53.8 \\
2.3 \\
1.7\end{array}$ \\
\hline $\begin{array}{l}\text { Education } \\
\text { percentage }\end{array}$ & $\begin{array}{l}\text { None } \\
\text { Primary } \\
\text { Secondary } \\
\text { Tertiary }\end{array}$ & $\begin{array}{l}23.2 \\
70.2 \\
6.4 \\
0.4\end{array}$ \\
\hline $\begin{array}{l}\text { Occupation } \\
\text { percentage }\end{array}$ & $\begin{array}{l}\text { Farmer } \\
\text { Ganyu } \\
\text { Salaried } \\
\text { Business } \\
\text { Student } \\
\text { No work }\end{array}$ & $\begin{array}{l}56.8 \\
1.2 \\
1.2 \\
4.4 \\
30.5 \\
5.9\end{array}$ \\
\hline $\begin{array}{l}\text { Marital status } \\
\text { percentage }\end{array}$ & $\begin{array}{l}\text { Married } \\
\text { Never married } \\
\text { Divorced } \\
\text { Widowed }\end{array}$ & $\begin{array}{l}55.5 \\
37.9 \\
4.3 \\
1.8\end{array}$ \\
\hline $\begin{array}{l}\text { Parity } \\
\text { percentage }\end{array}$ & $\begin{array}{l}\text { Ever pregnant } \\
\text { Never pregnant }\end{array}$ & $\begin{array}{l}58.2 \\
41.8\end{array}$ \\
\hline
\end{tabular}

Table 3: Key care and care seeking indicators of women or childbearing age in women's group intervention clusters (women aged 10 - 49 years) who became pregnant between january to June 2005

\begin{tabular}{|l|l|}
\hline $\begin{array}{l}\text { Women of childbearing age (aged 10 - 49) in } \\
\text { intervention clusters who became pregnant } \\
\text { between January and June 2005 }\end{array}$ & $n=1399$ \\
\hline $\begin{array}{l}\text { Any Voluntary Counselling and Testing of } \\
\text { HIV (VCT) during antenatal care (ANC) } \\
\text { Percentage }\end{array}$ & 11.7 \\
\hline $\begin{array}{l}\text { Slept under an insecticide treated net } \\
\text { (ITN) last night } \\
\text { percentage }\end{array}$ & 42.6 \\
\hline $\begin{array}{l}\text { Birth with a skilled provider } \\
\text { percentage }\end{array}$ & 36.0 \\
\hline $\begin{array}{l}\text { Birth with a traditional birth attendant } \\
\text { (TBA) } \\
\text { percentage }\end{array}$ & 41.2 \\
\hline $\begin{array}{l}\text { Wrapped baby within } 30 \text { minutes } \\
\text { percentage }\end{array}$ & 93.3 \\
\hline $\begin{array}{l}\text { Bathed baby after } 24 \text { hours } \\
\text { percentage }\end{array}$ & 31.5 \\
\hline $\begin{array}{l}\text { Initiated breastfeeding within one hour } \\
\text { percentage }\end{array}$ & 77.5 \\
\hline
\end{tabular}

